\title{
SEVERE THERMOMECHANICAL PROCESSING AS AN EFFECTIVE METHOD FOR THE PREPARATION OF BULK AND SHEET NANOSTRUCTURED SEMIFINISHED PRODUCTS FROM NICKEL ALLOYS 718 AND 718PLUS
}

\author{
V. A. Valitov ${ }^{1}$, R. R. Mulyukov ${ }^{1}$, M. F. X. Gigliotti ${ }^{2}$, and P. R. Subramanian ${ }^{2}$ \\ ${ }^{1}$ Institute for Metals Superplasticity Problems of Russian Academy of Sciences, 39. Khalturin Street; Ufa 450001, Russia \\ ${ }^{2}$ GE Global Research, One Research Circle; Niskayuna, NY, 12309 USA
}

Keywords: nanocrystalline structure, severe thermo-mechanical processing, 718, 718Plus, superplasticity.

\begin{abstract}
The paper considers the scientific basis of a new methodological approach for processing bulk and sheet nanostructured semi-finished products from nickel base alloys 718 and 718Plus. This approach involves carrying out severe thermo-mechanical processing (STMP) using primarily schemes of multiple isothermal forging (or forging followed by rolling) at temperatures decreasing gradually from $(0.9-0.8) \mathrm{T}_{\mathrm{m}}$ to $(0.6-0.5) \mathrm{T}_{\mathrm{m}}$. Such processing results in a step-by-step structure refinement: a coarse-grained macroduplex type structure transforms to a microduplex one $(d=1-3 \mu \mathrm{m})$ and then to a nanoduplex structure $(d=0.5-0.05 \mu \mathrm{m})$. The paper considers examples of production of complex profile turbine engines components from materials with a microduplex type structure and shows the possibility for applying semi-finished products with a nanoduplex type structure in advanced manufacturing procedures of pneumatic forming and pressure welding under low temperature superplasticity (LT SP) conditions.
\end{abstract}

\section{Introduction}

The nickel base alloys with pre-processed microcrystalline structure can display the effect of LT SP only at rather high homological temperatures $(0.8-0.85) \mathrm{T}_{\mathrm{m}}$ and low strain rates $\left(10^{-3}-10^{-4} \mathrm{~s}^{-1}\right)$, and thus prevents wide application of these materials in advanced manufacturing processes [1,2]. The expansion of manufacturing capacity of the SP effect by increasing strain rates and decreasing the temperature becomes possible due to the application of materials with submicrocrystalline (SMC; $0.9-0.3 \mu \mathrm{m}$ ) and nanocrystalline

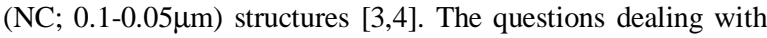
processing of materials with such structures, study of their physical and mechanical properties and development of efficient methods for manufacturing semi-finished products with NC structure $(0.5-0.05 \mu \mathrm{m})$ especially out of hard-todeform nickel base alloys are of immense interest $[5,6,7]$ to material science researchers. However, certain features of SMC and NC structure formation in highly alloyed nickel base alloys and their influence on SP behavior of the materials identified have not been investigated in detail previously. The opportunity for practical application of low temperature SP in new resourcesaving technologies for producing complex-profile structural parts also needs further study.

The goal of the present paper is to generalize the results of systematic studies of step-by-step transformation of the initial coarse-grained structure to the microcrystalline (MC), SMC and NC states for 718 and 718Plus nickel base alloys, and consider their effect on SP properties of these materials. Another goal is to evaluate the efficiency of practical application of semifinished products with specified structure in advanced manufacturing procedures for processing turbine engines components including the ones using the effect of LT SP.

\section{Materials and Experimental Procedure.}

Nickel base alloys 718 and 718Plus were used in the investigations. Bulk and sheet semi-finished products with specified structures were produced by STMP involving step-bystep multiple isothermal forging (or forging with following rolling). STMP was performed at temperatures decreasing stepby-step from $950^{\circ} \mathrm{C}$ to $570^{\circ} \mathrm{C}$. Investigations of the homogeneity of MC, SMC and NC structure formation were performed using cylindrical samples $8 \mathrm{~mm}$ in diameter and 12 $\mathrm{mm}$ in height subjected to uniaxial compression. For studying SP properties, flat specimens with the gauge dimensions $5 \times 2 \times 12 \mathrm{~mm}$ were tensile tested in a universal "INSTRON1185 " dynamometer over the temperature range $550-800^{\circ} \mathrm{C}$ and at strain rates $0.9 \times 10^{-4}-5.5 \times 10^{-4} \mathrm{~s}^{-1}$. Transmission electron microscopic studies were performed using a JEM-2000EX at an accelerating voltage of $160 \mathrm{kV}$. Foils for studies were cut from deformed semi-finished products and prepared using electrolyte of the following composition: butanol- $750 \mathrm{ml}$ chloric acid $50 \mathrm{ml}(\mathrm{I}=30-40 \mu \mathrm{A})$.

\section{Results of Investigations and Discussion}

$\underline{\text { Initial state }}$

Alloy 718 with nonisomorphic $\delta$-phase precipitates is a prominent representative of nickel-iron alloys with a large amount of iron ( 20-40\%). The strengthening of this alloy occurs due to precipitation of the nonisomorphic strengthening phase $\mathrm{Ni}_{3} \mathrm{Nb}$ in the form of disk-type coherent particles (metastable $\gamma^{\prime \prime}$-phase). In the process of long-term ageing or heating above $900^{\circ} \mathrm{C}$, this phase transforms into a thermodynamically stable orthorhombic $\delta$-phase structure of a plate shape [8]. Note that for generation of a microduplex structure in René 95-type alloys being strengthened due to precipitation of $\gamma^{\prime}$-phase $\left\{\mathrm{Ni}_{3}(\mathrm{Al}, \mathrm{Ti})\right\}$ these alloys should be subjected to pre-heterogenization annealing which results in maximum precipitation of hardening phase and its coalescence $[9,10]$. However, such processing is not advisable for nickeliron alloy 718 , since it would result in precipitation of brittle coarse $\delta$-phase plates. The length of these plates correlates with the grain size and their transformation into fine, non-coherent globular particles is rather difficult (Fig.1a). The TEM studies of alloy 718 have shown that its initial structure is of a microduplex type and completely recrystallized. Within coarse recrystallized $\gamma$ - phase grains, $40 \mu \mathrm{m}$ in size, there is a uniform dispersion of coherent disk-type $\gamma^{\prime \prime}$ - phase precipitates. The length of the coherent $\gamma^{\prime \prime}$-phase disks is $50-75 \mathrm{~nm}$ and their thickness is $20 \mathrm{~nm}$ (Fig.1b). An analogous structure but with less $\gamma$-phase grain size $(8 \mu \mathrm{m})$ is observed in alloy 718Plus (Fig. 1c). 

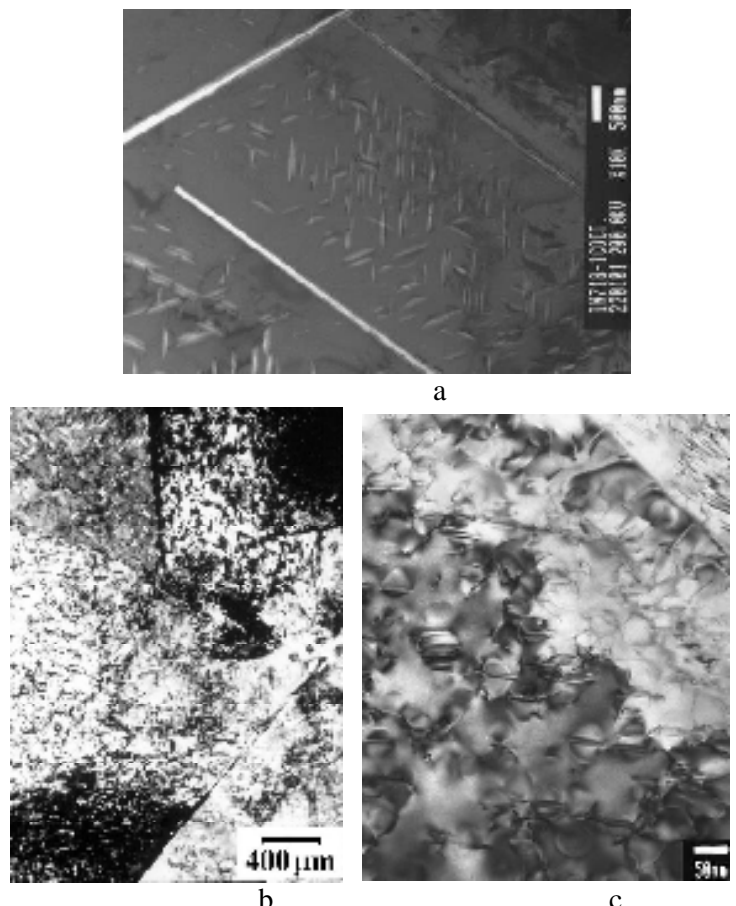

Figure 1. Microstructures of alloys $718(a, b)$ and 718Plus (c). a,c - initial coarse-grained structure; a - heterogenization annealing with slow cooling in a furnace $\gamma \Rightarrow \delta \Rightarrow \gamma^{\prime \prime}$-regions.

Formation of micro-, submicro- and nanocrystalline structures during STMP.

Based on the analysis of published studies [1-4, 5, 7, 9-12], as well as their generalization herein, a universal methodological approach for processing bulk and sheet nanostructured semifinished products from nickel base alloys with SMC and NC structures has been developed. This approach involves carrying out STMP using primarily schemes of all-round isothermal forging (forging followed by rolling) at temperatures decreasing gradually from $0.9-0.8 \mathrm{~T}_{\mathrm{m}}$ to $0.6-0.5 \mathrm{~T}_{\mathrm{m}}$. Such processing results in step-by-step structure refinement: a coarse-grained macroduplex type structure transforms to a MC structure of a microduplex type $(1-3 \mu \mathrm{m})$, and then at lower temperatures the $\mathrm{MC}$ structure transforms to SMC and further to NC (Fig. 2), i.e. structures of submicroduplex and nanoduplex types, respectively [11,13]. Fig.2 shows a scheme of step by step structure transformation during STMP, resulting in step- bystep refinement of the initial structure of a matrix (macroduplex) type to a nanoduplex state for alloys hardened by precipitation of isomorphic $\gamma$-phase particles.

Salient features of the step-by-step refinement of microstructure during STMP for alloy 718 are discussed below. At the first stage of processing over the temperature range $950-850^{\circ} \mathrm{C}$, the initial coarse-grained (CG) macroduplex structure $(\gamma$-phase grains, about $40 \mu \mathrm{m}$ in size, with a uniform dispersion of $\gamma^{\prime \prime}$ phase precipitates or $\delta$-phase plates) transforms to the MC structure of a microduplex type.

A thorough study of the mechanism of microduplex structure formation has shown that transformation of the coarse-grained structure to the MC structure of a microduplex type $(\gamma+\delta)$ occurs during hot deformation, when development of continuous dynamic recrystallization processes takes place [14].

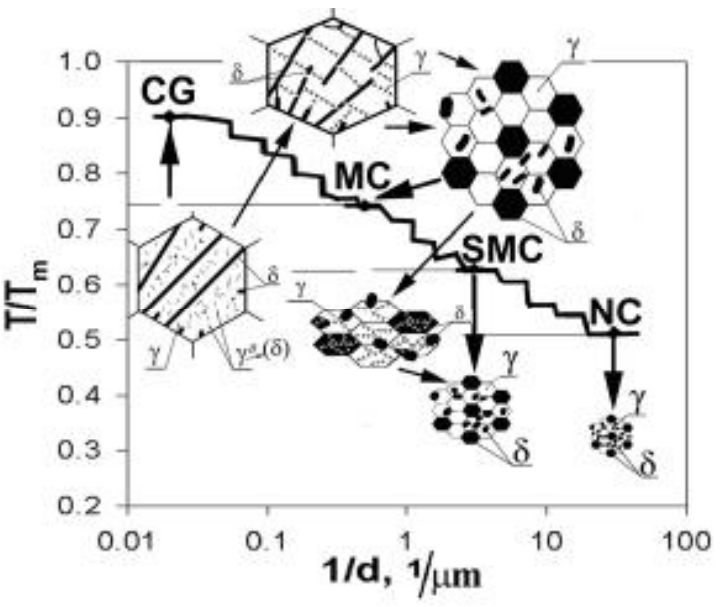

Figure 2. Scheme showing step-by-step refinement of microstructure during STMP at temperature decreasing gradually for nickel iron alloys strengthened by isomorphic $\gamma^{\prime}$-phase.

The investigation of microstructure evolution at the processing temperature $\left(925^{\circ} \mathrm{C}\right)$ revealed features of dynamic recrystallization (Fig.3) accompanied by precipitation of $\delta$ phase plates [11]. The development of intragranular dislocation slip at the initial stage of deformation (5-25\%) leads to formation of a subgrain structure. The size of the subgrains, especially ones adjacent to the initial boundaries, was comparable to the distance between $\delta$-phase plates (Fig.3b,d). With increasing strain, the density of dislocations rose and the volume fraction of $\delta$-phase plates became larger. The interaction of lattice dislocations with $\delta$-phase precipitates contributed to the development of multiple slip and increased misorientation between matrix generated subgrains. A further increase in the strain value resulted in transformation of the matrix subgrains into grains with high angle boundaries. Moreover, the growth of local stresses in the matrix near the $\delta$ phase particles led to flexure of the $\delta$-plates and formation of dislocation walls inside of the $\delta$-plates (Fig.3b,c). Due to the formation of new transverse subboundaries, where diffusion mass transfer is accelerated, $\delta$-plate fragmentation and spheriodization of separate fragments occured during further deformation. Concurrently with the change in morphology of the $\delta$-phase, there also occured changes in the structure of interphase boundaries: coherent $\gamma / \delta$ interphase boundaries transformed into non-coherent ones, having predominantly banded contrast being typical for high angle grain boundaries. The size of recrystallized $\gamma$-phase grains was $3 \mu \mathrm{m}$, while the size of non-coherent particles, $\delta$-phase grains of an ellipsoidal shape that were separated from matrix grains by high angle grain boundaries, was $0.5-1.5 \mu \mathrm{m}$ (Fig.3e).

Mechanical properties of the samples subjected to uniaxial compression within the temperature range of $550-950{ }^{\circ} \mathrm{C}$ at a strain rate of $1 \cdot 10^{-3} \mathrm{~s}^{-1}$ are presented in Fig. 4a. Comparison of the deformation curves of Alloy 718 and Allvac 718Plus with the average grain sizes of $15 \mu \mathrm{m}$ and $8 \mu \mathrm{m}$, respectively, showed a higher flow stress (by 100-250 MPa) for the Allvac 718 Plus in the investigated temperature range. 
According to the data shown in Fig.4b, a decrease in the level of flow stress during STMP resulted in a step-by-step refinement of the structure from CG to MC and then to SMC and $\mathrm{NC}$ scales. For example, at the temperature $0.8 \mathrm{~T}_{\mathrm{s}}$, the decrease in the grain size from $40 \mu \mathrm{m}$ to $1-3 \mu \mathrm{m}$ (MC), reduced the level of flow stress by a factor of 3 . One should note that alloy 718 with MC structure displayed high values of working plasticity at the temperature $0.8 \mathrm{~T}_{\mathrm{s}}\left(800^{\circ} \mathrm{C}\right)$ since this temperature is a lower temperature threshold of SP for this structural state [4].

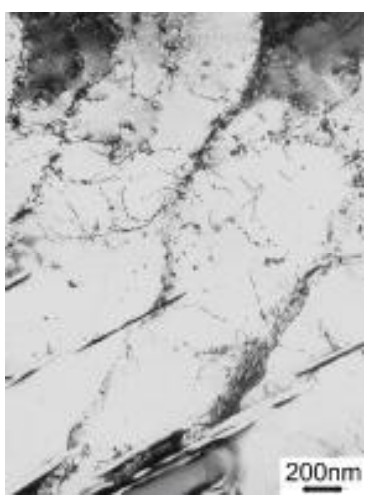

a

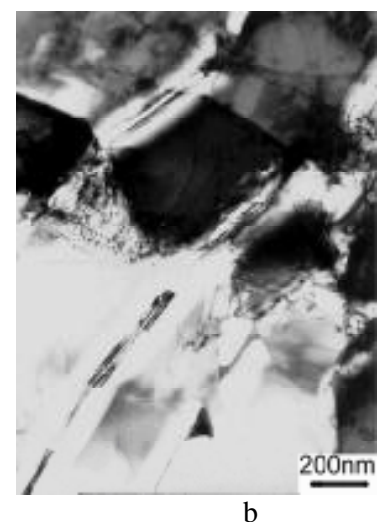

b

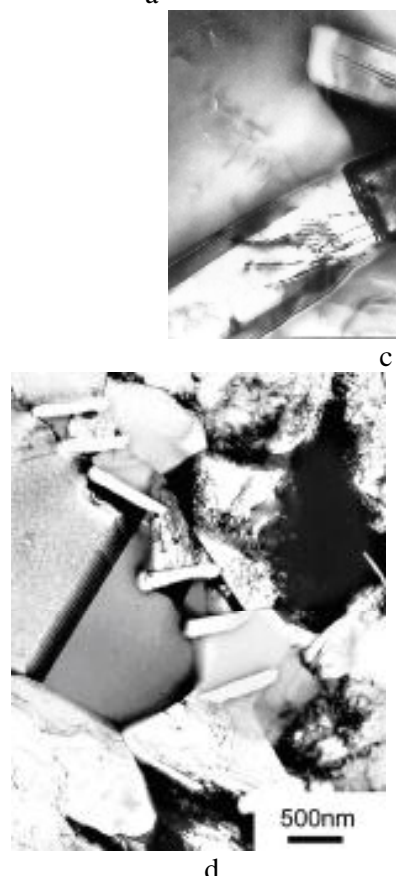

d

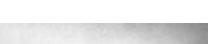
.

slip the dominating mechanism of low temperature SP. This factor is very important as it promotes recrystallization in SMC materials at low homologous temperatures unlike the CG materials where recrystallization is not possible at these temperatures.

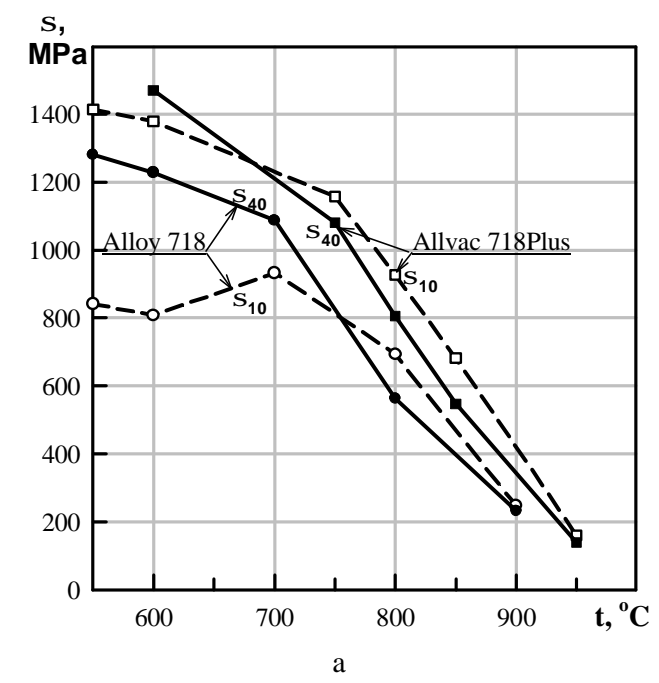

Figure 4a. Dependence of flow stress $\sigma$ at plastic strains of $10 \%$ and $40 \%$ versus deformation temperature $\mathrm{t}$ for alloys 718 and Allvac 718Plus at a strain rate of $1 \cdot 10^{-3} \mathrm{~s}^{-1}$.

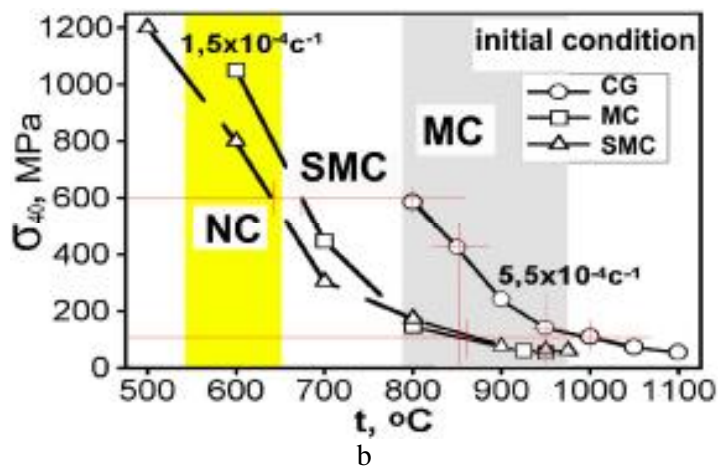

Figure $4 \mathrm{~b}$. Temperature ranges for formation of $\mathrm{MC}, \mathrm{SMC}$ and NC structures in alloy $718 . \sigma_{40^{-}}$ flow stress after deformation by $40 \%$ (uniaxial compression).

In the deformation of alloy 718 with the initial SMC structure of a submicroduplex type (Fig.5a) at $600^{\circ} \mathrm{C}$, continuous dynamic recrystallization and additional precipitation of $\delta$ phase particles takes place, which lead to formation of grains with a mixed cellular-subgrain structure inside of the SMC grains. Generation of $\gamma^{\prime \prime}$-phase is retarded because of high density of dislocations in SMC structure. With increasing strains, this structure transforms to the NC structure mainly with high-angle intergranular $\gamma / \gamma$ boundaries. One should note that the presence of $\delta$-phase particles, located mainly along $\gamma$ grain boundaries, exerts an influence on the formation of dislocation structure in the deformed material. At the same time, the intragranular dislocation sliding induces local overstresses at interphase boundaries between the matrix and a plate-like SMC $\delta$-phase fragment. As a result, the shorter $\delta$ phase plates fragment, and finer NC fragments are formed. In the process of further spheriodization these $\mathrm{NC}$ fragments 
transform into non-coherent grains of a globular shape, that is randomly oriented with respect to matrix grains and separated high angle $\gamma / \delta$ interphase boundaries (Fig.5c).

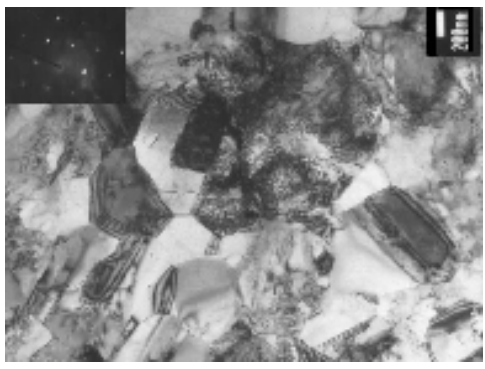

a

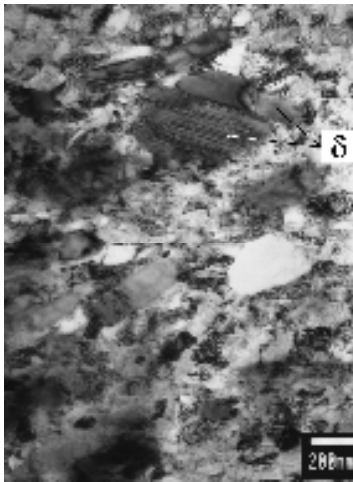

b

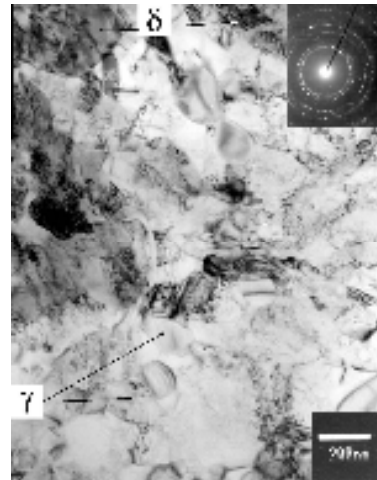

c
Figure 5. Microstructure of alloy 718 . a) SMC structure; b) structure of the alloy after deformation by $50 \%$ at the temperature $600^{\circ} \mathrm{C}$; c) NC structure after STMP (all-round forging at the temperature $600^{\circ} \mathrm{C}$ ).

The temperature-strain rate conditions $\left(600^{\circ} \mathrm{C}, 1.5 \times 10^{-4} \mathrm{~s}^{-1}\right)$ under which the SMC material was deformed were similar to those under which the forming NC structure displayed the effect of LT SP [4]. It is not surprising that the development of dynamic recrystallization at low homologous temperatures is facilitated by grain boundary processes, including grain boundary sliding. In the SMC state, the intergranular and interphase boundaries become dominating sites for the generation of lattice dislocations, which are necessary for deformation via intragranular dislocation slip. The increased role of grain boundary sliding is confirmed indirectly by the increase of the coefficient $\mathrm{m}$ by a factor of 2 in the SMC material that is deformed by $75 \%$ at $600^{\circ} \mathrm{C}$, as compared to the value $\mathrm{m}$ in the initial stage of deformation $(10 \%)$ that is correlated with the results obtained earlier [14]. Grain boundary processes play an essential role [15], since they provide conditions for developing both dislocation-rotary and rotary deformation mechanisms of deformation, the effect of which is connected with the generation of a cellular structure and its further transformation into the $\mathrm{NC}$ structure.

Thus, STMP performed in the temperature-strain rate regime corresponding to the conditions for forming an SP structural state is an efficient method for processing bulk semi-finished products with uniform SMC or NC structure. The step-by-step deformation using a scheme of all-round forging provides high strains $(\varepsilon \geq 1-3)$. The intermediate annealing at the temperature equal to the temperature of forging or slightly below promotes further development of recrystallization processes that started at deformation. As a result, the processes of continuous recrystallization developed both at deformation and at annealing are repeated many times, and provide for an increased recrystallized volume of the NC structure.

The investigations of alloy 718Plus have shown that analogous MC, SMC and NC structures can be formed in this alloy (Fig.6).

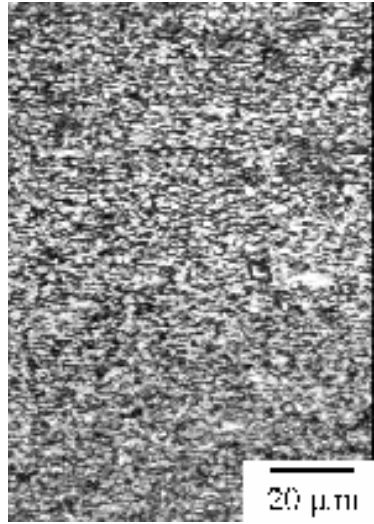

a

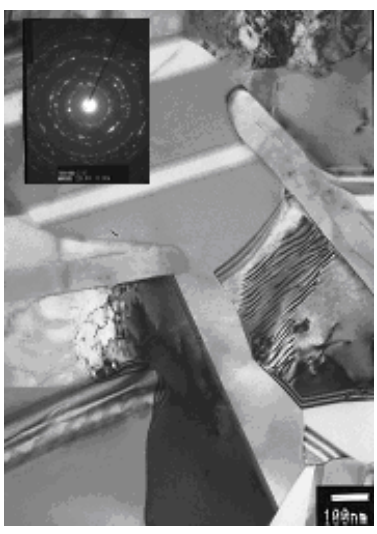

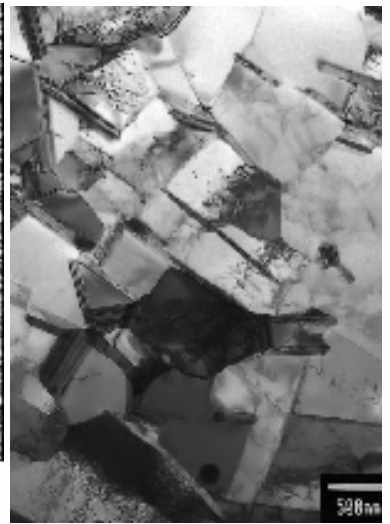

b

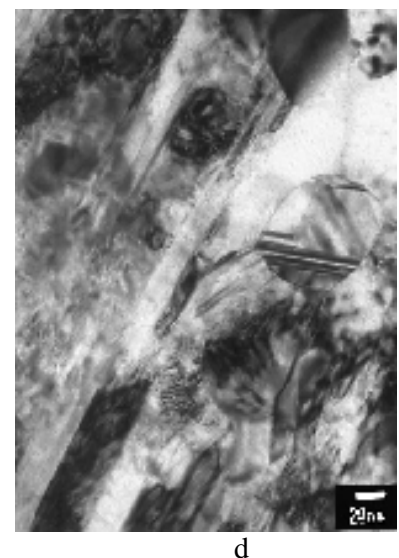

d

Figure 6. Microstructure of alloy 718Plus after deformation at strain rate $=5 \cdot 10^{-4} \mathrm{~s}^{-1}$ :

$\mathrm{a}, \mathrm{b}-\mathrm{MC}, 950^{\circ} \mathrm{C} ; \mathrm{c}-\mathrm{SMC}, 900^{\circ} \mathrm{C} ; \mathrm{d}-\mathrm{NC}, 750^{\circ} \mathrm{C}$.

The results obtained in the present work are compared with data on deformation behavior and microstructure changes for 718Plus at isothermal compression [11-13]. Differences in the chemical composition alloy 718 Plus versus alloy 718 , such as a decrease in $\mathrm{Fe}$, introduction of $\mathrm{Co}(9.1 \%)$, and others result in increased thermal stability of its structure, due to higher $\gamma^{\prime} / \gamma^{\prime \prime}$ solvus $\left(989^{\circ} \mathrm{C}\right)$ and $\delta$ solvus $\left(1060^{\circ} \mathrm{C}\right)$ temperatures. As a result, the formation of MC, SMC and NC structures occurred at higher homologous temperatures. Moreover, under similar processing conditions the level of flow stress in alloy 718Plus is higher by $25-200 \mathrm{MPa}$ especially at the deformation temperature below.

The results of microstructure studies of the deformed 718Plus indicated that the temperature ranges of $\mathrm{MC}, \mathrm{SMC}$ and $\mathrm{NC}$ structure formation are shifted to $50-150^{\circ} \mathrm{C}$ higher homologous temperatures than in alloy 718 . So, the well-characterized 
STMP regimes for nickel alloys 718 and 718Plus provides for the generation of different structures whose features are dictated by the required processing characteristics of SP semi-products in terms of component features and service properties requirements.

\section{Low temperature superplasticity of alloy 718 .}

The grain size refinement to NC scale provides LT SP at much reduced temperatures [13]. In particular, the NC alloy 718 displays features of LT SP at temperatures as low as $575^{\circ} \mathrm{C}$. Table I lists experimental measurements of LT SP in NC alloy 718. The alloy with an initial NC structure in the temperaturestrain rate range under study displays maximum values of relative elongation $(580 \%)$ and strain rate sensitivity factor, $\mathrm{m}$, at the deformation temperature $700^{\circ} \mathrm{C}\left(0.65 \mathrm{~T}_{\mathrm{m}}\right)$ and strain rate $3 \times 10^{-4} \mathrm{~s}^{-1}$, thus showing evidence of LT SP. LT SP in alloy 718 is observed at $600^{\circ} \mathrm{C}$ and strain rate $3 \times 10^{-4} \mathrm{~s}^{-1}$, which is confirmed by high values of relative elongation $(253 \%)$ and coefficient $\mathrm{m}(0.35)$. The comparison of these data with the results obtained earlier [5] has shown that the two-fold decrease in the strain rate (from $3 \times 10^{-4} \mathrm{~s}^{-1}$ ) reduces the relative elongation to $350 \%$ and a value of flow stress $\sigma_{40}$ (by a factor of 1.8) from 752 to $414 \mathrm{MPa}$. This suggests that the optimum temperature of LT SP $\left(600^{\circ} \mathrm{C}\right)$ at which the structure is still thermally stable is within the range of lower strain rates $\left(10^{-5}\right.$ $\left.10^{-6} \mathrm{~s}^{-1}\right)$

Table I. Superplastic properties of alloy 718 with initial NC structure

\begin{tabular}{|c|c|c|c|c|}
\hline $\begin{array}{c}\text { Temperature of } \\
\text { deformation, C }\end{array}$ & $\begin{array}{c}\text { Strain rate, } \\
\mathrm{s}^{-1}\end{array}$ & $\delta, \%$ & $\begin{array}{c}\sigma_{40}, \\
\mathrm{MPa}\end{array}$ & $\mathrm{m}$ \\
\hline 800 & $5.5 \times 10^{-4}$ & 323 & 128 & 0.4 \\
700 & $3 \times 10^{-4}$ & 580 & 230 & 0.4 \\
650 & $3 \times 10^{-4}$ & 342 & 310 & 0.34 \\
600 & $3 \times 10^{-4}$ & 253 & 752 & 0.35 \\
600 & $1.5 \times 10^{-4}$ & 350 & 414 & 0.37 \\
575 & $1.5 \times 10^{-4}$ & 173 & 880 & 0.27 \\
550 & $0.9 \times 10^{-4}$ & 160 & 1017 & 0.25 \\
\hline
\end{tabular}

SP can be applied to form precise shapes out of nickel base alloys. The achievement of new, high efficiency processes for manufacturing complex-profile parts under SP conditions is possible only in the presence of MC and SMC structures that provide high values of ductility and low flow stress at SP deformation [1-4, 9-14].

It should be noted that with decreasing STMP temperature, the labor-intensiveness of the process for producing superplastic semi-finished products increases due to the increase both in the power and force requirements of the process and the number of passes. This requires an efficient selection of STMP regimes for processing a specified structure (MC or SMC), which can be applied further in a technological process for producing articles under SP conditions.

Semi-finished products with MC structure are most optimal for producing disk type articles by means of local forming (rollforming or rotary drawing) under SP conditions [1, 12]. For example, processing of a simple shape forging for further rotary drawing from a large scale billet $200-250 \mathrm{~mm}$ in thickness and $400 \mathrm{~mm}$ in width out of alloy 718 with initial CG structure was performed concurrently with the formation of a MC structure [16]. Roll-forming (rotary drawing) was performed at a temperature within the two-phase $\gamma+\delta$-region, and a uniform
MC structure was formed in the rolled portion of a flange-type component (Fig.7). The investigation of structure and properties of roll-formed components has shown that after standard thermomechanical processing, a sufficiently fine-grained structure $(12-16 \mu \mathrm{m})$ was preserved in disks, which provides increased short-term strength and ductility at room and elevated temperatures. The high temperature properties of samples cut from the processed disk completely meet the required specifications.
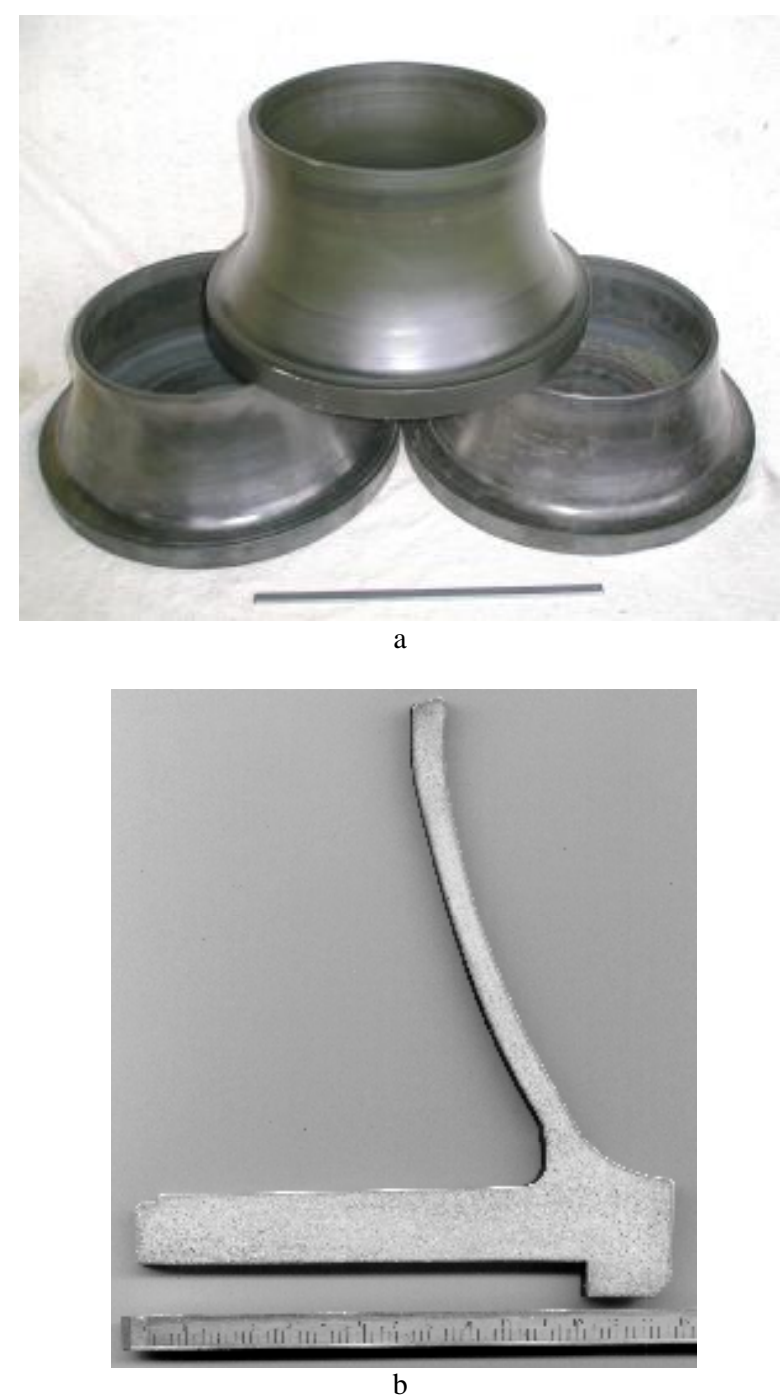

Figure 7. General view (a) and macrostructure (b) of disks out of alloy 718, produced by rotary drawing under SP conditions.

For processing sheet semi-finished products with MC and SMC structures out of hard-to-deform nickel base alloys, it is advisable to apply a processing scheme by which, at the first stage of processing, a massive semi-finished product with MC structure is produced. At the second stage, the massive semifinished product is subjected to isothermal or quasi-isothermal rolling for processing a sheet of a required thickness with the SMC structure.

It has been experimentally established [17,18] that the formation of a SMC structure permits SP forming and pressure 
welding under conditions of LT SP. Systematic studies of the influence of different structures (CG, MC, SMC) on solid state weldability were performed using alloy 718 [17]. A sound nonporous solid state joint was produced at temperatures 150 $200^{\circ} \mathrm{C}$ lower than the those of current processes. Moreover, it has been shown that a solid-state joint can be formed from samples of the same material but with different structures, for example, CG-MC, CG-SMC or MC-SMC (Fig.8). It was determined that the temperature of solid state joining depends on the SP properties of the sample with finer structure, and the finer the structure, the lower the temperature at which solid state joining is achieved.
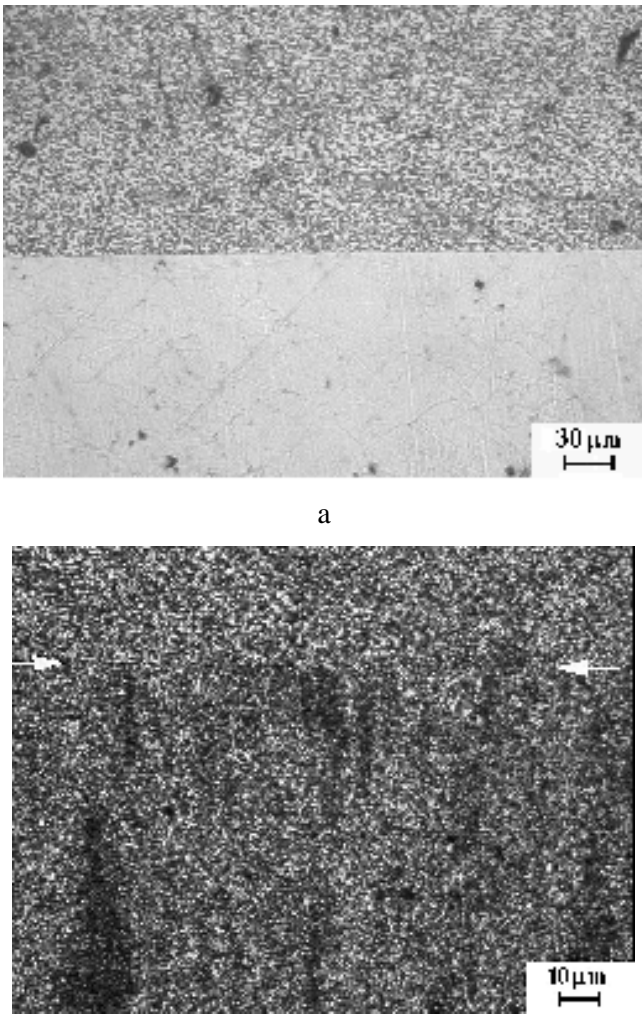

b

Figure 8. Zones of solid state joining of samples with different structures under conditions of LT SP (alloy 718)

a-CG+MC, $850^{\circ} \mathrm{C} ; \quad$ b-MC+SMC, $750^{\circ} \mathrm{C}$.

\section{Conclusion}

An approach was developed that provides refinement of an initial coarse-grained structure to a nanocrystalline structure by means of STMP with a step-by-step decrease in processing temperature. The practical implementation of this approach includes processing to specified (MC, SMC, or NC) structural conditions in semi-finished products and articles, imparting required LT SP characteristics. Final thermal processing and heat treatments are used to achieve required service properties. This work is a result of long-term cooperation between IMSP RAS and GE Global Research and financial and technical support of these organizations. Additionally, financial support and programmatic guidance of the International Science and Technology Centre is gratefully acknowledged.

\section{References}

1. O.A. Kaibyshev, F.Z. Utyashev, V.A. Valitov, "Influence of $\gamma^{\prime}$-phase content on regimes of structure processing and SP of high temperature nickel alloys"// MiTOM, 7 (1989), 40-44.

2. O.A. Kaibyshev, F.Z. Utyashev, «Superplasticity: Microstructural Refinemant and Superplastic Roll Forming». (Futurepast . Arlington, Virginia USA. 2005.), 386.

3. V.A. Valitov, G.A. Salishchev, Sh. Kh. Mukhtarov "Superplasticity of Nickel base superalloys with Submicrocrystalline Structure", Izv. RAN, Metally, 3 (1994), 127-131.

4. V.A. Valitov, O.A. Kaibyshev, Sh. Kh. Mukhtarov, B.P. Bewlay, M.F.X. Gigliotti, "Low Temperature And High StrainRate Superplasticity Of Nickel Base Alloys", Proceedings of the «International Conference On Superplasticity In Advanced Materials, ICSAM-2000»,Orlando, USA. - 2001),. 417 - 424.

5. N.I. Noskova, R.R. Mulyukov Submicrocrystalline and nanocrystalline metals and alloys.(Ekaterinburg: UrO RAN, 2003, 279.

6. R. Z. Valiev, I. V. Alexandrov, Bulk nanostructured metallic materials. (M.: Akademkniga, 2007), 398.

7 .R. R. Mulyukov, "Development of processing principles and investigation of bulk nanostructured materials in IMSP RAS", Rossyiskie nanotekhnologii, 2 (7-8) (2007), 38-53.

8. Superalloys II. High temperature materials for aerospace and industrial apparatus Ed. C.T. Sims, N.S. Stoloff, W.C. Hagel, Transl. from Eng. In books . Book 1/ Ed. Shalin P.E.(M.: Metallurgiya, 1995), 384.

9. F. Z. Utyashev and V. A. Valitov, "Regimes of Thermomechanical Treatment for Producing Ultrafine-Grained Structures in Heat-Resistant Nickel Alloys," Tekhnol. Legk. Splav., 2 (1989), 63-67.

10. O. A. Kaibyshev, V. A. Valitov, G. A. Salishchev. Phys. Met. Metallogr., 75 (1993), 409-414.

11. B.P. Bewlay, V. A. Valitov, O.A. Kaibyshev, Sh.Kh. Mukhtarov, C.U. Hardwicke and M.F.X. Gigliotti, "Mechanisms of Grain Refinement and Superplastic Behavior of Alloy 718", Microstructure modeling and prediction during thermomechanical processing. (Proceedings of Symposium of TMS. Indiana, USA. Edited by R. Srinivasan, S. L. Semiatin, A. Beaudoin, S. Fox, Z. Jin. A Publication of TMS. - 2001), 175-185.

12. V. A. Valitov "Superplasticity of high temperature nickel alloys with macro-, submicro- and nanocrystalline structures and prospects of its application for processing complex profile components", Tyazheloe mashinostroenie, 4 (2007), 23-28.

13. V. A. Valitov, Sh. Kh. Mukhtarov, Yu. A. Raskulova, "Formation of nanocrystalline structure during severe deformation thermal processing and its effect on superplastic properties of nickel alloy with non-isomorphic precipitates of second phase", FMM, 1 (2006), 105-113. 
14. V. A. Valitov, O. A. Kaibyshev, Sh. Kh. Mukhtarov, N. R. Gajnutdinova, "Formation of Micro-, Submicro- and Nanocrystalline Structures in Nickel-Base Alloys" (Proceedings of the First Joint International Conference "Recrystallization and Grain Growth", Springer-Verlag. 2001), $563-568$.

15. N. I. Noskova, N. F. Vildanova, and. R. V. Churbaev, "Formation of Nano-Sized Grains in Al-Based Alloys upon Severe Plastic Deformation", Phys. Met. Metallogr., 99 (2005), 159-165.

16. V.A. Valitov, O.A. Kaibyshev, Sh. Kh. Mukhtarov, B. P. Bewlay, C. U. Hardwicke, M.F.X. Gigliotti, "Production Of Large-Scale Microcrystalline Forgings For Roll Forming Of
Axially Symmetric Alloy 718 Components", (5th Intl Special Emphasis Symposium On Superalloys 718, 625, 706 \& Derivatives.- Pittsburgh, USA. 2001), 301-311.

17. V. A. Valitov, R. Ya. Lutfullin, Sh. Kh. Mukhtarov, M. Kh. Mukhametrakhimov, "Pressure welding underv superplastic deformation of nickel alloy Inconel 718", Perspectivnyui materially 6,( 2004), 78-83.

18. V. A. Valitov, R. V. Safiullin, Sh. Kh. Mukhtarov, "Superplasticity of alloy Inconel 718 with submicrocrystalline structure “, Perspectivnyui materially, 4 (2007), 53-58. 